\title{
Enhancing the Structural Performance of Masonry Structures by Post-Tensioning
}

\author{
Leonardo Todisco' ${ }^{1}$ - Elizabeth Stocks $^{1}$ • \\ Javier León ${ }^{1}$ • Hugo Corres ${ }^{1}$
}

\begin{abstract}
Despite the evident advantages of combining masonry with prestress, their joint use has been poorly exploited during the last decades. This paper claims the high potential of masonry as a primary load-bearing material when combined with post-tensioning. This work deals with arch footbridges and antifunicular structures. With respect to the first, this research illustrates the introduction of external loads by internal post-tensioning to favourably increase the axial forces in a masonry arch, and consequently improving its structural behaviour. With respect to the second, this work shows how bending moments in a non-funicular $2 \mathrm{D}$ curved geometry can be eliminated through an external post-tensioning system. In summary, this research strongly expands the range of post-tensioned masonry structures that exhibit a bending-free (or quasi bending-free) behaviour and, de facto, opens up new possibilities for designs that combine structural efficient solutions with traditional materials.
\end{abstract}

Keywords Masonry $\cdot$ Prestress $\cdot$ Post-tensioning $\cdot$ Bending-free $\cdot$ Funicular behaviour · Equilibrium

Leonardo Todisco

lt@he-upm.com

Elizabeth Stocks

elizabethstocks@gmail.com

Javier León

jlg@he-upm.com

Hugo Corres

hcp@he-upm.com

1 Universidad Politécnica de Madrid, Prof. Aranguren s/n, 28040 Madrid, Spain 


\section{Introduction}

\section{Background}

The history of construction can be depicted as a constant battle against tensile stresses or, at the very least, the search for a way to avoid them. Indeed, the development of structural members working by shape (arches and vaults), or the use of tensile-bearing materials such as wood or iron-if properly connected at the ends-exemplifies the above statement. The pioneers of reinforced concrete thought that the alliance of both materials (formicus and ferrum), occasionally in combination with rather funicular and antifunicular shapes of structural members (i.e. Gaudí's architecture), would free designers of classical forms and materials consolidated by tradition. This 21 st century brings the opportunity of enlarging and projecting such ideas to other structural materials, masonry included. More than two centuries of using Physics and Mathematics (and Chemistry as well) to the construction-considered as science since then-have multiplied the height, span and speed of construction by 50 or more. In fact, the development and dissemination of the strength of materials, which consecrated a mathematical conception of structural behaviour, has undoubtedly contributed, in conjunction with the quality of materials and construction equipment, to the extraordinary progress of structural engineering. Nevertheless, paradoxically, such abundance of tools and materials runs the risk of limiting understanding and designing. In other words, the theory of bending or the finite element method, whose power and efficiency is irrefutable, could impair, in principle, the ability to understand the structural mechanics from a different point of view. It is the authors' experience, especially when dealing with masonry structures, that other engineers have some difficulties in understanding old concepts such as "line of thrust" or the theorems of Plasticity. Engineers must be aware that there are other ways of understanding and designing structures. Such procedures, although perhaps forgotten, are also available to explore new possibilities, both in the domain of designing new structures and retrofitting the existing ones.

The aim of is paper is to show a couple of examples of this different, although not exactly new, approach applied to the conceptual design of masonry structures.

\section{Scope of the Research}

Masonry rarely plays a leading load-bearing role in modern structures due to its economical and constructive difficulties. Its utilization has been mostly left to secondary elements such as paving, façade or cladding. In spite of that, this paper is addressed at claiming the potential of masonry as a primary load-bearing element, specifically when it is combined with post-tensioning. The advantages of the joint use of these materials has been acknowledge for centuries (Viollet-le-Duc 1863; Campa 2009; Fallacara and Brocato 2010), however, its employment has been poor during recent years. More specifically, this paper explores the possibility of using 
this idea for the design and construction of arch footbridges and antifunicular structures.

\section{Organization of the Paper}

This paper presents an original research addressed at exploring the possibility of combining masonry and post-tensioning for the design and construction of materialefficient structures. The paper is structured as follows: first, a brief state-of-the-art is presented; herein several examples of existing structures with active prestressing systems combined with masonry are briefly illustrated. The following sections discuss two case studies, differentiating between internal and external posttensioning. Firstly, the application of this concept to internal post-tensioned masonry arch footbridges is described in depth. This chapter includes a typological study and the related structural analysis. Secondly, an original general theory and its implementation are introduced for eliminating bending moments in a curved masonry structure through external post-tensioning systems. Next, the procedure is applied to several free-form geometries. Finally, conclusions and future work are discussed.

\section{State of the Art}

The intuition of changing the distribution of loads to achieve a better structural behaviour is very old. In fact, the shape of Roman constructions, commonly built with a circular geometry, does not correspond to the antifunicular geometry of its self-weight, which for a constant-thickness arch is a catenary. However, Roman builders applied different techniques (i.e. backfill, variable material density, etc.) to indirectly achieved better structural stability by changing the distribution of the permanent loads (Ramos-Casquero 2016) (Lancaster 2005). A more recent existing example of this concept is represented by the façade of the Pavilion of the Future (Fig. 1), built in Seville for the Universal Exposition in 1992, and designed by Peter Rice of Ove Arup and Partners and Mortell, Bohigas and Mackay (Brown 2001). The main design concept takes advantage of the gravity loads generated by the roof beams in order to apply a set of equal radial forces on the circular arch of the façade, forcing the thrust line to pass closer to the centroid line of the arch (Lenczner 1994).

The façade structure, shown in Fig. 2 adapted from (Lenczner 1994), is one of the key elements of the building, employing an innovative structural system that combines stone and steel. The load-bearing structure of the façade has to work only in compression because it is made of discrete masonry elements. If only the distribution of the arch's self-weight was considered (Fig. 2a), the geometry chosen for the arch, the semicircle, would collapse because the thrust line is not contained within the masonry thickness (Fig. 2b). Therefore, a thicker arch size would normally be required to resist internal bending moments (i.e., eccentricity of the thrust line). Aware of this problem, the designer modified the external loading on the arch with a series of radial struts (Fig. 2c), tensioned by the weight of the adjacent roof. This changed the dominant loading on the arch so that the thrust line 


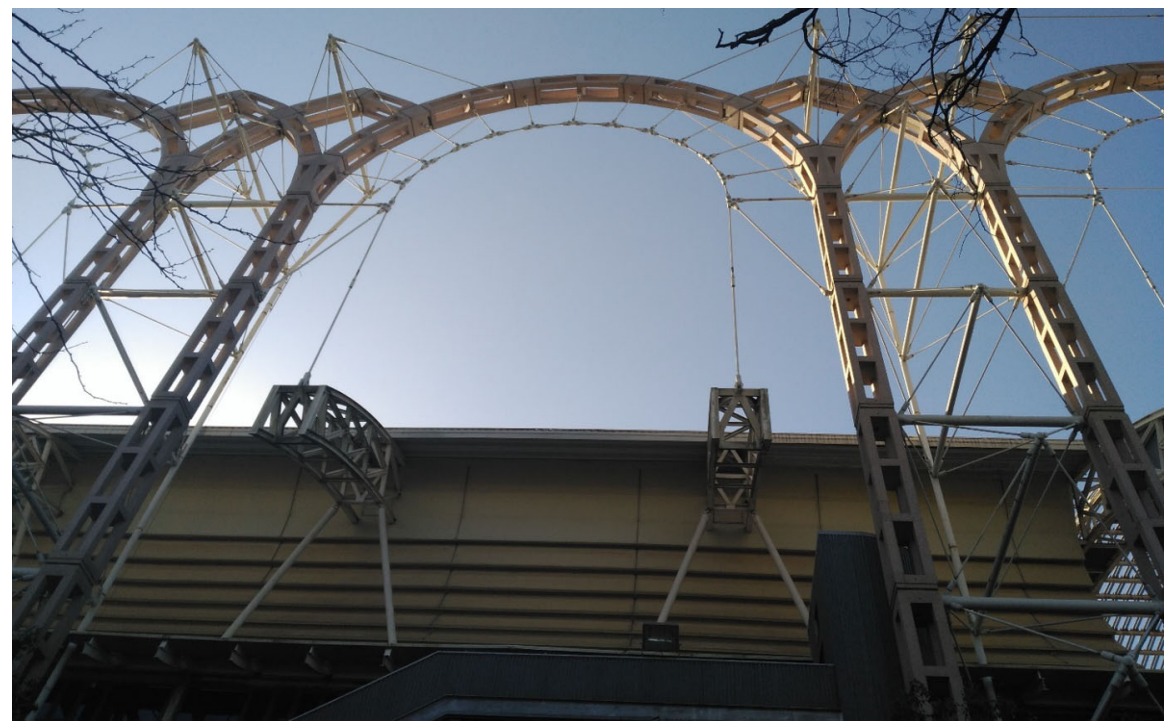

Fig. 1 Photo of the Façade of the Pavilion of the Future (credits: authors)

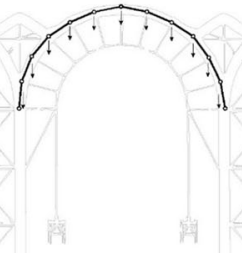

(a)

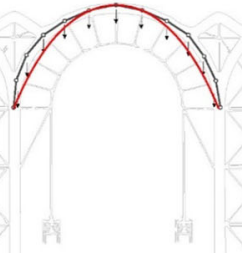

(b)

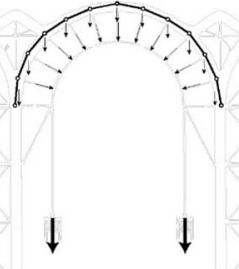

(c)

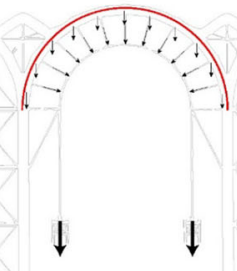

(d)

Fig. 2 Structural concept behind the Façade of the Pavilion of the Future (credits: authors)

was closer to the semi-circular shape and enabled the structure to achieve stability (Fig. 2d).

However, the application of external loads as hanged weights, often, is not a possible solution. An alternative option consists in intelligently employing external post-tensioning to generate the required external loads. The concept of prestressing became a reality through the development of a new material (high-strength steel) and novel construction techniques during the first decades of the 20th century (Lin 1963). Prestressing allows the redirection of the gravitational forces to achieve the desired internal force distribution (Leonhardt 1964). The historical development of external post-tensioning is even more recent; most applications are related to reinforced concrete bridges (Ruiz-Teran and Aparicio 2007; Misiunaite 2013) and post-tensioning has rarely been employed in combination with masonry. However, there are contemporary works that successfully take advantage of the mechanical characteristics of stone, in a large number of different solutions that are good 
examples of the present and future possibilities of the use of masonry as a fundamental load-bearing material, especially for footbridges.

One of the first examples of this successful combination is represented by the 34 m-span Inachus footbridge, designed by Mamoru Kawaguchi and built in Oita (Japan) in 1994 (Fig. 3). The bridge has a lenticular shape with an arched upper chord and a suspended lower chord, connected to each other by means of web members consisting of steel tubes arranged to form inverted pyramids. The lower chord, made of steel plates arranged into a chain, has the longitudinal shape of a funicular polygon (this guarantees a constant force), which is almost symmetrical to the upper chord. The upper chord, which plays a dual role of a principal structural member and deck floor, is a circular arch and consists of 78 blocks of granite (compressive strength around $130 \mathrm{MPa}$ ) with a width of $40 \mathrm{~cm}$, depth of $25 \mathrm{~cm}$ and a varying length from 2.6 to $3.6 \mathrm{~m}$. Through holes drilled in the center of the depth of the granite blocks, 5 prestressed cables are arranged in the longitudinal direction, parallel to each other (Fig. 3). After the joints between the adjacent granite blocks are secured with filling mortar, the whole upper chord is prestressed to produce a literally monolithic structural member. Readers more interested in this bridge can refer to the following references (Sanmartín 1998; Kawaguchi and Mamoru 2002; Strasky 2005; Romo and Jose 2017).

One of the main advantages related to the combined use of prestressing with stone, instead of concrete, is the lack of rheological effects due to creep and shrinkage. This allows the designer to take full advantage of prestress, by strongly increasing its efficiency over time. The German company Kusser Aicha Granitwerke has moved this concept to reality by designing and building several prestressed concrete footbridges (Fig. 4). These minimalistic prestressed stone footbridges take advantage of the high compressive strength of granite (around $200 \mathrm{MPa}$ ) to span, at maximum, 20 meters and with a span-to-depth ratio of around 50. This result is quite impressive if compared with a prestressed concrete footbridge that generally has a span-to-depth ratio of 20-25. The prestressing tendons are anchored at the dry-joint end blocks (unbounded post-tensioning). As exemplified in the Inachus footbridge, the structural material (granite) also serves
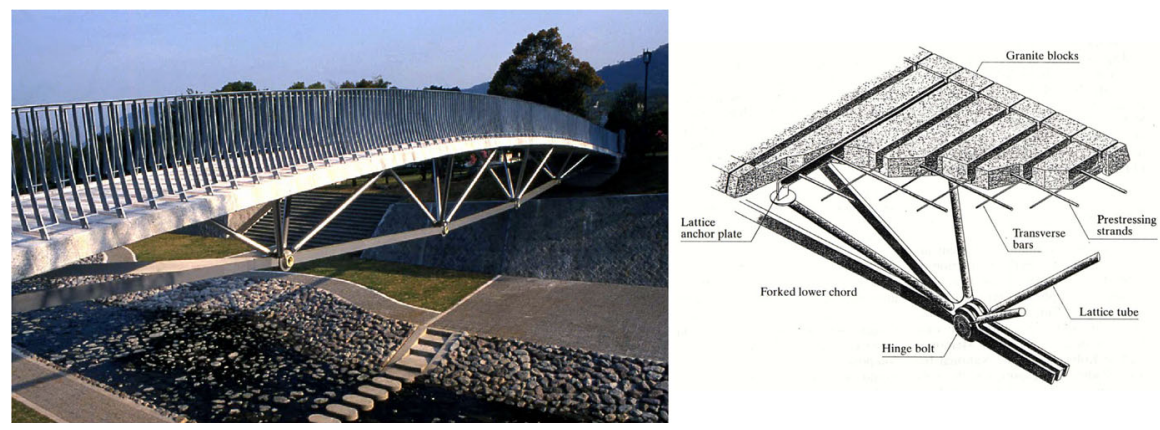

Fig. 3 Inachus Footbridge. On the left: picture of the bridge (credits: Kawaguchi and Engineers); on the right: detail of the connection between top and bottom chords (Kawaguchi and Mamoru 2002) 


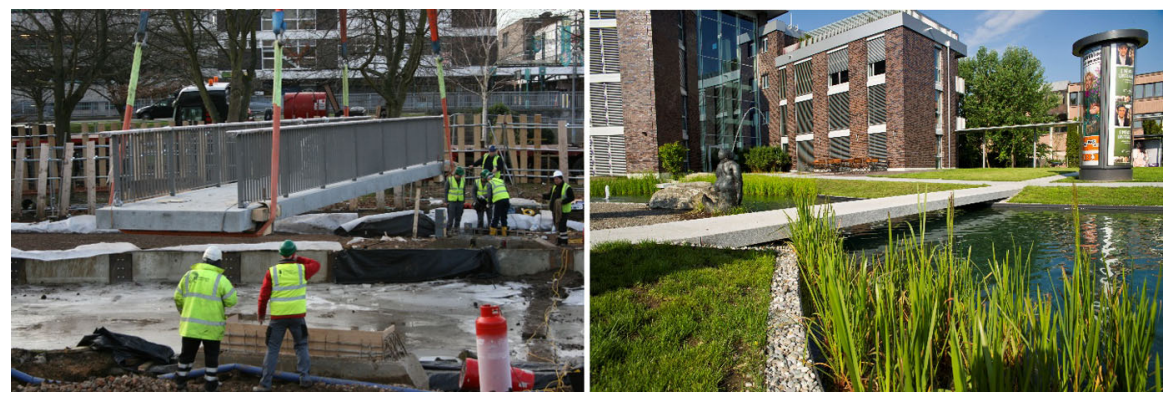

Fig. 4 Post-tensioned granite footbridges (Credits: https://www.kusser.com)

directly as the deck surface. The durability is guaranteed by the prestress, which does not allow crack openings, and, especially, by PE ducts filled with grease.

An unusual application of masonry in bridge design is represented by the footbridge across Hessenring in Bad Homburg v. d. Höhe by Schlaich Bergermann and Partners (SBP) in 2002 (Fig. 5). The footbridge is 46 meters long and 7 meters wide. The slab is suspended by 16 hangers, which transfer loads to a tree-like mast composed by individual block of natural gabbro. The blocks are aligned at a central steel rod and fastened.

The post-tensioning technology combined with masonry is not restricted to footbridges; it can also be applied to many other structural typologies, enabling designers to control the structural behaviour of curved structures, e.g., shells, arches, roofs, etc. (Strasky 2003). An interesting application of post-tensioning to stone building is represented by the Queen's Building, Emmanuel College, located in Cambridge (UK) (Dickson and Werran 1999). Here, 28 post-tensioned Ketton stone columns compose the perimeter frame of the 4-store building. The post-tensioning system was applied by using grade 316 stainless steel with dead-end anchorage located at the bottom of each column. The project included a wide series of mechanical tests on small specimens, 10 scaled-down columns and 2 large-scale columns. These tests allowed defining a characteristic strength of $12.5 \mathrm{MPa}$, which was reduced to a design strength of $4.1 \mathrm{MPa}$. Another remarkable example of posttensioning stone applied to buildings can be found in the design of the Padre Pio
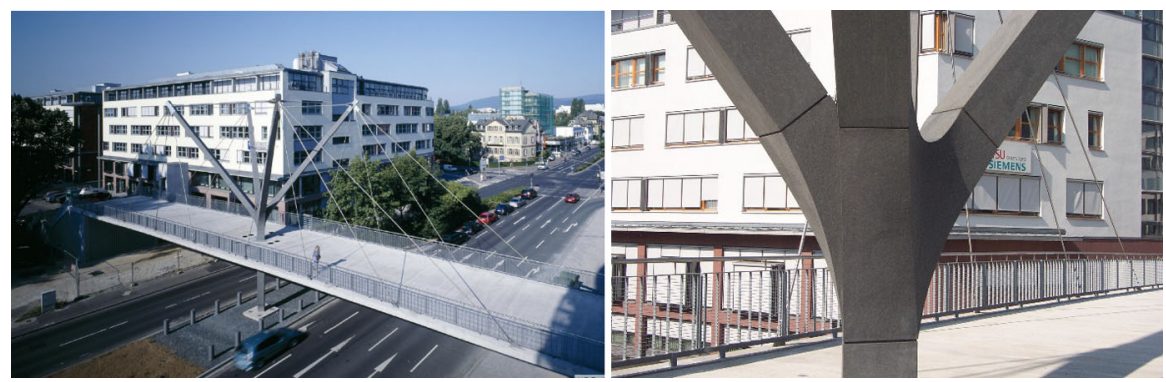

Fig. 5 Footbridge across Hessenring. On the left: picture of the footbridge; on the right: tree-like masonry mast (Credits: https://www.sbp.de) 
Church in San Giovanni Rotondo, Italy (Fig. 6) (Potenza 2005). Post-tensioning is used in the construction of a series of 17 stone arches which support the roof. The largest of the arches has a span of $45 \mathrm{~m}$ and rise of $5 \mathrm{~m}$. They were constructed using large marble blocks bedded in epoxy resin mortar. Laminated steel plates were also used to ensure the proper connection between blocks. The fact that this creative structure was built in an area prone to earthquakes, demonstrates the foresight and creativity of the main engineer Peter Rice.

When working with stone, maintaining the correct geometry and mechanical properties of the material is essential. In this case, many tests were carried out to guarantee the homogeneity of the material and to prevent any cavities or fractures in the blocks. The non-destructive techniques were then corroborated by other destructive activities (Dernie 2003). Recently, architects of the New Fundamentals Research Group (Politecnico di Bari) and engineers from Universitá degli Studi Roma Tre, have designed and built the 'HyparGate' - the first discrete hyperbolic paraboloid made of stone-in Troyes, France (Fig. 7). The installation covers an area of around $44 \mathrm{~m}^{2}$ and it is composed of a 100 discrete blocks with a thickness of $0.16 \mathrm{~m}$ (i.e. each one of them as a weight of $120 \mathrm{~kg}$ ). Despite of its well-known use for structural purposes, the hyperbolic paraboloid is not an antifunicular shape for its self-weight; in fact, the elements with downward concavity work in compression, while the elements with upward concavity work in tension. The main concept behind the masonry HyparGate is to replace reinforced concrete with post-tensioned stone with steel bars (Malomo et al. 2015, Fallacara et al. 2017). The authors specify that the necessary amount of prestressing is around $8 \mathrm{kN} / \mathrm{m}$, i.e. $45 \mathrm{kN}$ for each steel bar. The bars are located in a specific space between block edges in order to avoid stone drilling.

Another extraordinary example of the use of post-tensioning in stone can be found in the Helical Stone Stairs designed by The Stone Masonry Company together with Webb Yates Engineers. Each of the steps of this $4.6 \mathrm{~m}$ diameter floating staircase is made of a unique limestone block. The slenderness and weightless appearance was achieved by means of two $12.9 \mathrm{~mm}$ steel cables that run along the center of the blocks (Fig. 8). The prestress allowed for a reduction of the weight due to the centralizing of the stresses in the cross section.

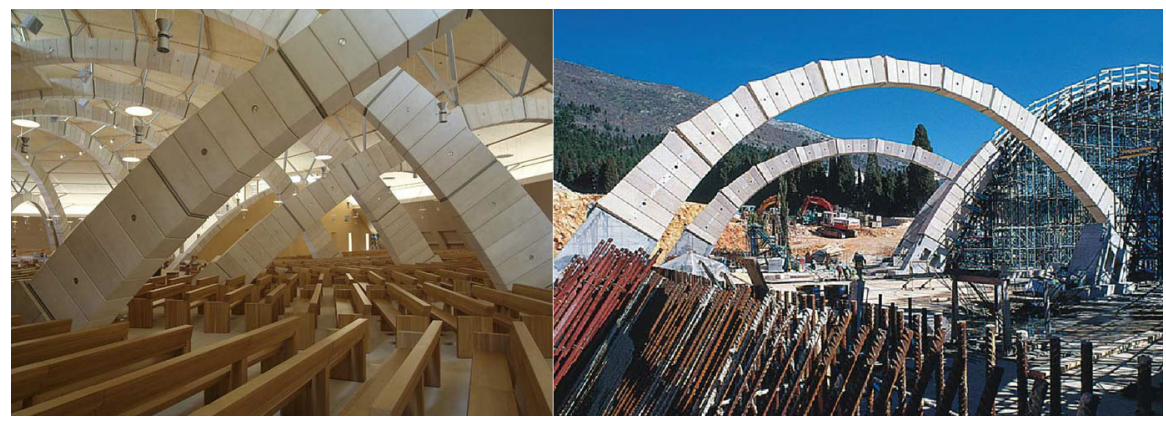

Fig. 6 Padre Pio Church (Credits: Renzo Piano Building Workshop https://www.rpbw.com) 


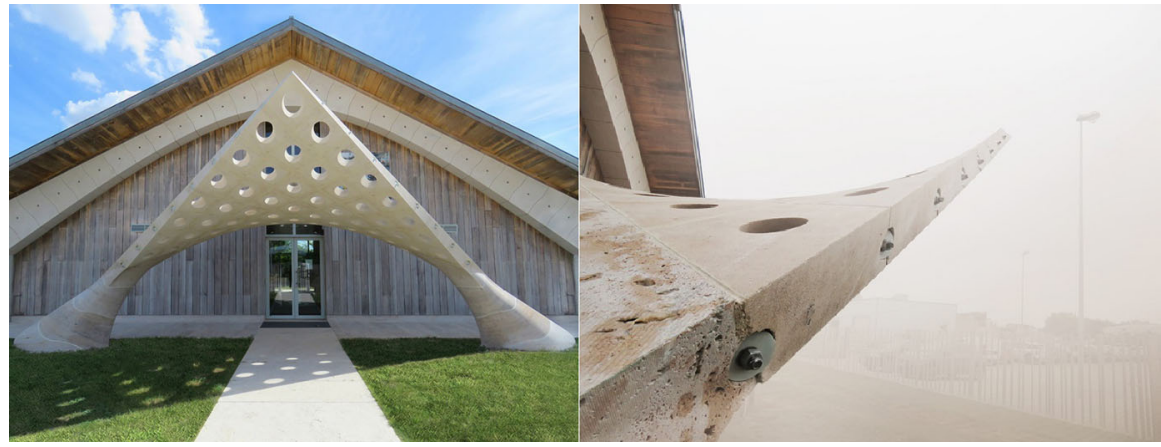

Fig. 7 HyparGate. On the left: picture of the installation; on the right: detail of the post-tensioning (Credits: New Fundamentals Research Group)
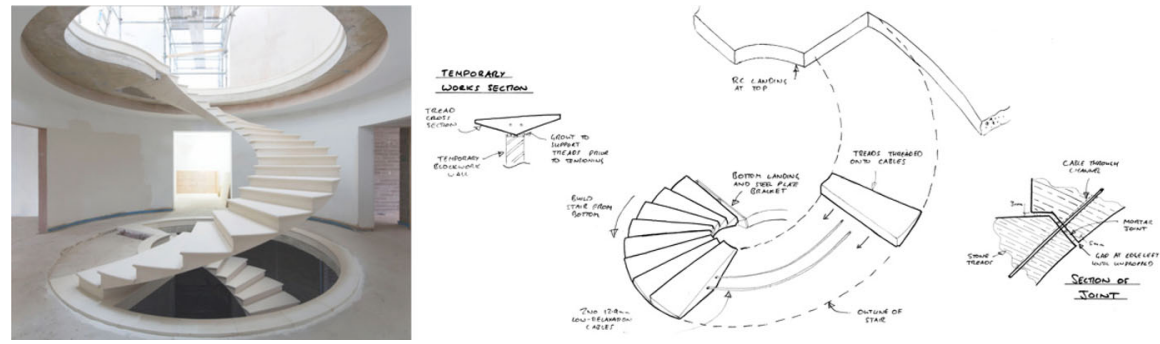

Fig. 8 Helical Stone Stairs. On the left: picture of the stairs; on the right: detail of the post-tensioning (Credits: Agnese Sanvito and Webb Yates Engineers; https://www.webbyates.com)

Although the technique of post-tensioning masonry is quite new, it is seen more frequently and in larger scale structures. Jordi Faulí, the architect in charge of La Sagrada Familia in Barcelona, has stated that they will implement this technique for 800 panels that form part of the central towers of the basilica; in fact, prestressing will allow for a higher resistance to winds with less weight.

In 2015, the town of Broto (Huesca, Spain) launched a contest for a new footbridge over the River Ara. The new structure would partially replace an existing masonry bridge, whose two spans were blown up in 1938. The crossing would link two cities' neighborhoods taking advantage of the ruins of the existing bridge dating back to 1532. FHECOR Consulting Engineers submitted the proposal described in Fig. 9, based on a post-tensioned masonry arch, which uses the existing abutment and pier as abutments of the new vault. The proposal, which was not selected for the final design, would have a span-to-rise ratio of 14 and a span-to-thickness ratio of 87. The local stone would assume the load-bearing role whilst the built-in prestress would allow to achieve an unusual slenderness. In this way, the new footbridge would respect the existing ruin that is the true protagonist of the crossing.

Today there is a renovated interest in discontinuous stone structures: this is mostly due to the technology developments in the field of robotics and computer integrated manufacturing which are reducing considerably the fabrication time, minimizing wastes and optimizing the stone cutting process (Colella 2017). 


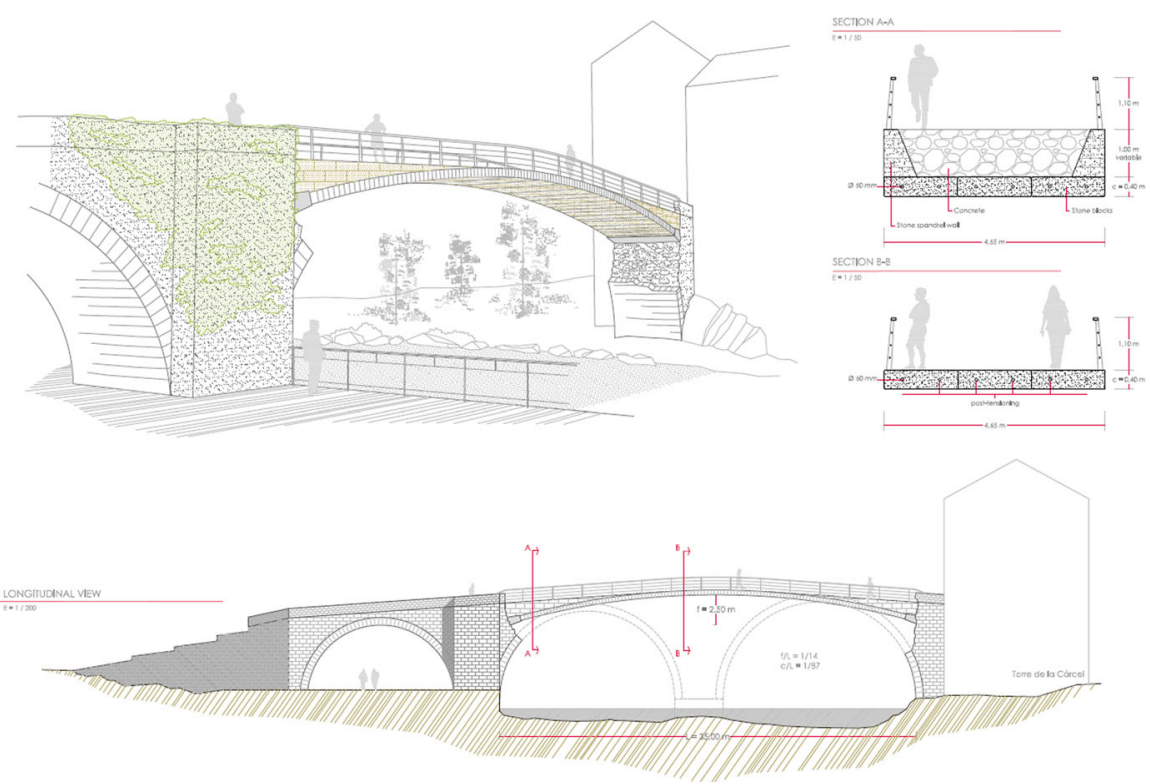

Fig. 9 Proposed footbridge by FHECOR Consulting Engineers for a new crossing in the city of Broto (Credits: authors)

In spite of that, according to the authors, the combination of masonry and prestressing has not been fully exploited. The next chapters explore two new structural typologies that take full advantage of this combination for design that combine slenderness, material-efficiency and durability.

\section{Conceptual Design of Post-Tensioned Masonry Arch Footbridges}

\section{Typological study}

This section presents the study of post-tensioned masonry arch footbridges; specifically, it describes the parametric study that was initially developed in order to evaluate the feasibility of the proposed solution for the Broto footbridge, previously mentioned. This research is detailed in the master's thesis carried out by the second author (Stocks 2017). The raison d'être of this solution is to provide an additional resistance capacity to masonry vaults which is achieved with the introduction of prestress through internal post-tensioning. The benefits obtained are present at both a sectional and structural level. Prestressing allows for an increase in both stability and load-bearing capacity without the additional load that is achieved, in more traditional arches, with the backfill contained between spandrel walls. This results in the possibility of designing much more slender structures (i.e. higher span-tothickness ratio). In this research, different geometries were evaluated with 
slenderness values ranging from 50 to a 100, and span-to-rise ratios ranging from 8 to 20 .

For an efficient design and ease of construction, only circular shaped arches and tendons running along the centroid of the barrel are considered. The post-tensioning is necessarily centred as it is the best way to resist the envelope of all load combinations. Additionally, when the tendons' layout follow a circular path, the external and internal forces (deviation forces) generated are perfectly autoequilibrated since the radius of curvature is constant. By the same token, prestressing also presents benefits against in-plane buckling of the arch. Any modification from the original form would modify the deviation forces in such a manner that they would return the deformed arch to its original form, having a stabilizing effect (Fig. 10).

Prestressing is intended as unbonded, since it has the advantages of providing a higher corrosion protection, negligible friction and easy inspection, maintenance and replacement if needed. Some prestress loss might still occur due to the contact between the cable and the anchors as well as the application of the force. However, this loss is considerably smaller compared to a bonded prestressing.

It is worthy to point out that the robustness of the structure is fully ensured, since, even without prestressing, the structure, in its final configuration, continues to be stable under self-weight and dead loads.

\section{Structural Analysis}

The analysis of post-tensioned masonry arches is based, according to the safe theorem of the plasticity theory, on finding the possible thrust lines contained within the structural thickness of the arch (Heyman 1966). It is an iterative process in which, starting from initial geometrical and load distribution data, a first solution is explored and subsequently modified until the final solution is reached. This solution must satisfy both rise and thickness requirements.

The following data must be previously defined:

- $\operatorname{Span}(l)$.

- Rise $(f)$.

- Thickness (c), assumed to be constant for ease of construction.

- Typology of backfill and spandrel walls.

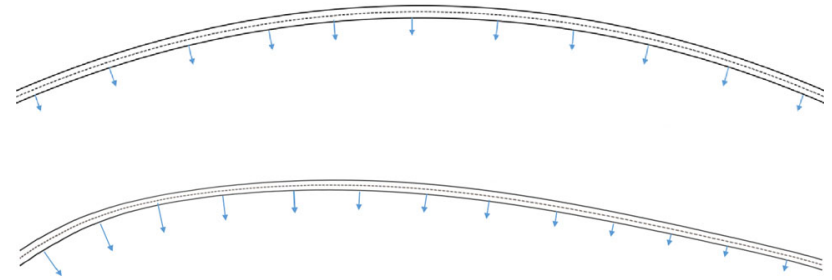

Fig. 10 Deviation forces in arch bridge. On top: constant curvature and equal magnitude of deviation forces. On bottom: Lower magnitude of deviation forces where the radius curvature is higher and vice versa 
- Prestress force $(P)$.

- Applied loads.

The analysis shown here considers a horizontal roadway, located at " $c$ " $\mathrm{m}$ (the thickness) above the extrados of the barrel at crown.

For each load combination, the thrust lines with the maximum and minimum rise are computed by modifying the external forces applied (Fig. 11). It has to be pointed out that this analysis considers only applied loads, while the effects of imposed deformations are not taken into account. This criterion provides the boundary stability situations before collapse takes place under the form of a kinematic mechanism. The thrust line theory is entirely based on equilibrium and is independent of the material's mechanical properties. Afterwards, to ensure that the masonry does not crushes (ultimate limit state) or undergoes excessive compression (service limit state) the structure is analysed at sectional level. Alternative numerical analysis procedures can be employed to investigate the behaviour of these structures. Specifically, discrete element modelling (Colas et al. 2013) may be suitable for this study because it would allow to consider the structure as a series of independent elements, hypothesis closer to the real behaviour of these structures. In this case, more refined data regard to the mechanical properties of masonry are needed. A combined behaviour of stone and mortar is considered following Ohler's simplified formula to estimate the masonry's strength. This formula depends greatly on the ratio of block's heights to mortar's thickness (Martinez 2003). In summary, the selected limit thrust lines take into account geometrical and mechanical constrains.

Note that if the infill material is assumed to be competent (rigid), the thrust line could pass through the backing. However, this is not considered to be on the safe side.

In order to acquire a better understanding of the behaviour of prestressed masonry arches, the influence of the two main parameters (slenderness and span-to-
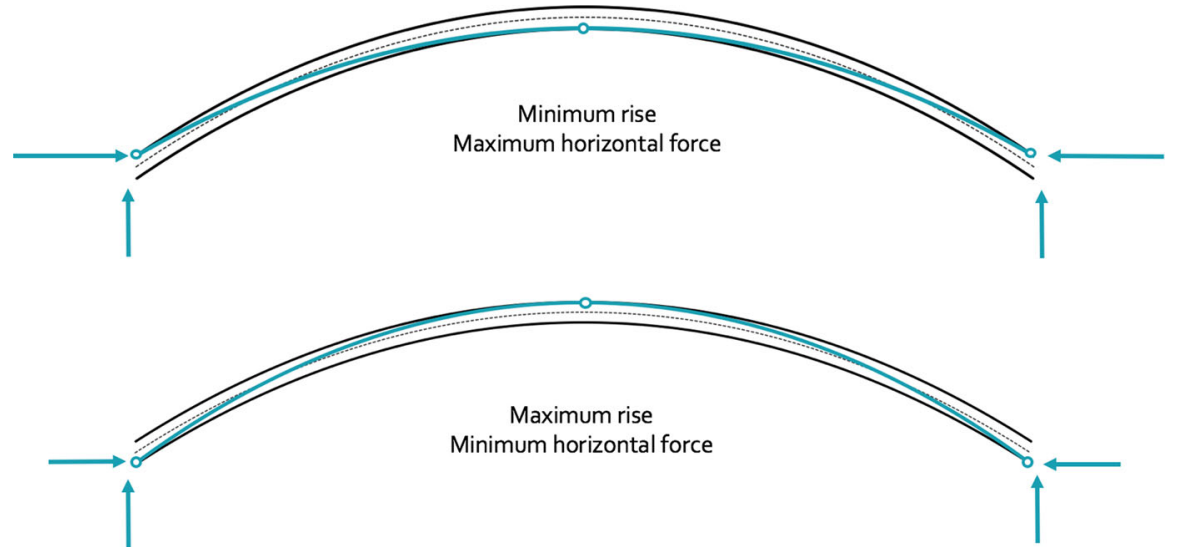

Fig. 11 Minimum and maximum rise thrust lines are determined by modifying the external reactions and their position. Any feasible solution shall be intermediate between the corresponding upper and lower horizontal forces (minimum and maximum rise of the thrust line, respectively) 
rise ratio) on the external reactions were evaluated. Figure 12 shows the maximum and minimal horizontal reactions $\left(\mathrm{R}_{\mathrm{H}}\right)$ obtained for two fixed span-to-rise ratios (i.e. 12 and 16). The analysed arch is $30 \mathrm{~m}$ long and $1 \mathrm{~m}$ wide, under the action of selfweight and dead loads. Although slenderness and span-to-depth ratios are nondimensional, there was no simply way of defining a non-dimensional ratio related to the reaction (through the total weight, for instance), since its value depends on the slenderness and span-to-rise ratios as well. This does not condition neither the purpose nor the conclusions of the study. As can be expected, a greater span-to-rise ratio (green) will yield a higher horizontal reaction. However, as the slenderness increases, the horizontal reaction reduces. Furthermore, it has to be noted that as the slenderness increases, the boundary lines come closer together. This means that there is a smaller range of stable solutions, indicating a lower margin of safety. The point where the two lines would eventually cross represents the highest slenderness possible for a predetermined combination of loads. In this case, any additional eccentric load would modify the thrust line and would result in the collapse of the structure.

Afterwards, different levels of prestress were introduced to evaluate its influence. In Fig. 13, the dotted blue lines represent the maximum and minimum horizontal reaction forces for a footbridge with a span-to-rise ratio of 16 without prestressing. Once the prestress is applied, the range of possible horizontal reactions increases, which can be appreciated in the continuous lines, moving outwards. The advantages of this effect are more palpable when asymmetrical loads are introduced into the structure. The optimal prestress force to be applied needs to be sufficient to significantly increase the bending moment capacity whilst still staying far from reaching the material's compressive strength. This optimal level of prestress was

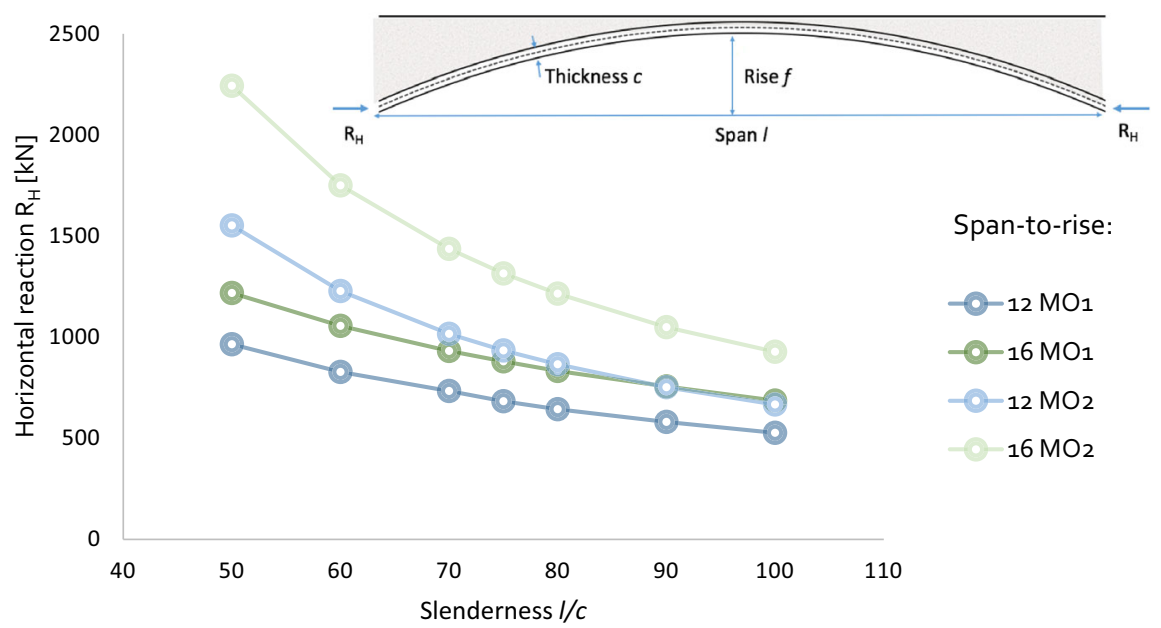

Fig. 12 Horizontal reaction for different values of the slenderness and span-to-rise ratios. MO1: collapse mechanism with maximum rise of thrust line (min. reaction). MO2: collapse mechanism with minimal rise of thrust line (max. reaction) 


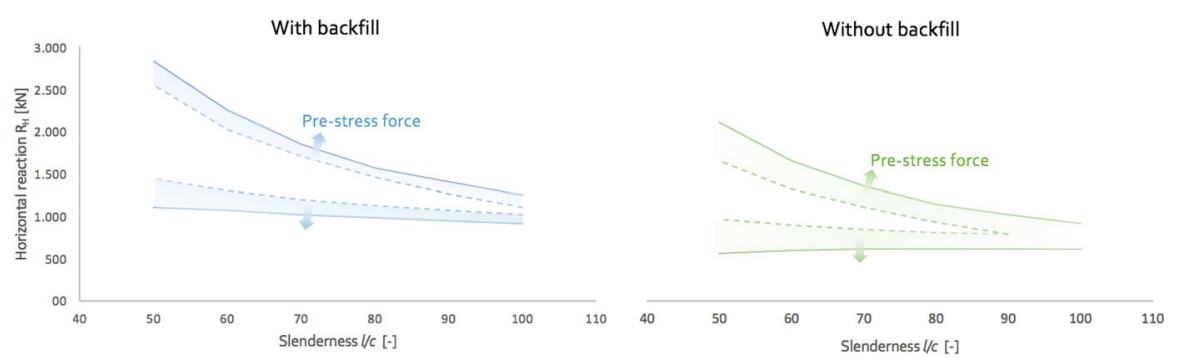

Fig. 13 Comparison of the horizontal reactions with and without prestress and backfill

determined to be approximately three times the medium horizontal reaction. As a result, the prestress force depends on both slenderness and span-to-rise ratio.

Lastly, defining an adequate span-to-rise ratio is important for reaching maximum efficiency. A footbridge with a low span-to-rise ratio increases the backfill necessary to fulfil the slope requirements for pedestrian traffic. As a result, the inherent prestress effect of the backfill diminishes the benefits of the posttensioned tendons in terms of bending capacity, but on the other end, increases the horizontal reactions. On the contrary, a higher span-to-rise ratio decreases the deviation forces due to a higher radius of curvature. The horizontal reaction would also be very high and could condition the construction of the footbridge. As it can be seen in Fig. 13, when no backfill is applied, the total horizontal reaction decreases and the gap between the situations (i.e. with and without the prestress force) increases, implying a higher margin of safety.

\section{Construction Process}

While masonry arch bridges have always been admired for both their structural and aesthetic qualities, very few of them have been built in recent years. To some extent, it is because they could not compete in terms of speed of construction with modern prestressed concrete and steel systems. The convenience that post-tensioned masonry presents is that all the blocks, voussoirs, are equal in geometry and therefore interchangeable. The footbridge can be built on top of a framework on the side of the stream allowing for minimal impact on the environment and a reduction of the cost. Once all the voussoirs are in their final position, the tendons are threaded and prestressed. The footbridge can then be lifted and placed on top of the abutments at the bridge site. The construction of the spandrel wall and backfill would follow and finally the finishing construction stages. If needed, an additional prestress could be introduced once the footbridge is in its final position.

The moment and amount of prestress force applied at each stage of the construction determines the behaviour of the structure and effectiveness of the whole system. An initial prestress, before lifting the footbridge, allows for the deviation forces to be completely auto-equilibrated with the external forces of the prestress. A second alternative, based on prestressing the footbridge once it is in its final position, can present many challenges in the construction stage. However, the advantages of this second option are that the external forces reduce the horizontal 
reaction that is transmitted to the abutments (this is analogous to tying the abutments together). Since these footbridges are designed with very high span-torise ratios, completely eliminating the large horizontal reaction would require equally high prestress forces. Nevertheless, even partially reducing this force would reduce the total cost of the abutments. A third option can be considered where prestress is applied in two stages utilizing the best of both alternatives.

\section{Conceptual Design of Post-Tensioned Masonry Antifunicular Structures}

\section{Methodology}

This section presents an apparent different issue: a new design approach, based on graphic statics that shows how bending moments in a two-dimensional geometry can be eliminated by adding forces through an external post-tensioning system. This results in bending-free (i.e. compression-only) structures that provide innovative answers to combined demands on versatility and material optimization.

The theoretical framework is based on the technique of graphic statics, which relates structural geometry and internal forces through reciprocal polygons (Cremona 1872; Culmann 1864; Pirard 1967; Wolfe 1921). The concept of the funicular polygon for simply-connected structures (also known as Cremona or Cremona-Maxwell diagram) and force polygon was firstly introduced by Varignon (Varignon 1725), and later extended to analyze trusses and beams. It was the most employed design method until the end of the first third of the 20th century. The virtues of this method for form-finding structures have only been published recently (Allen and Zalewski 2009; Fivet and Zastavni 2012, 2015; Van Mele et al. 2012). The approach is graphical in the sense that forces are geometrically calculated from the force polygon. The graphical construction to convert a non-funicular shape into a bending-free one is described in detail in other authors' papers (Todisco et al. 2015, 2016; Todisco and Corres 2017). Here, it is shortened in two main steps, and applied to a circular arch (Fig. 14). It consists in:

- Step 1: Definition of the external point forces (blue continuous lines) to be applied to the structure to make it bending-free.
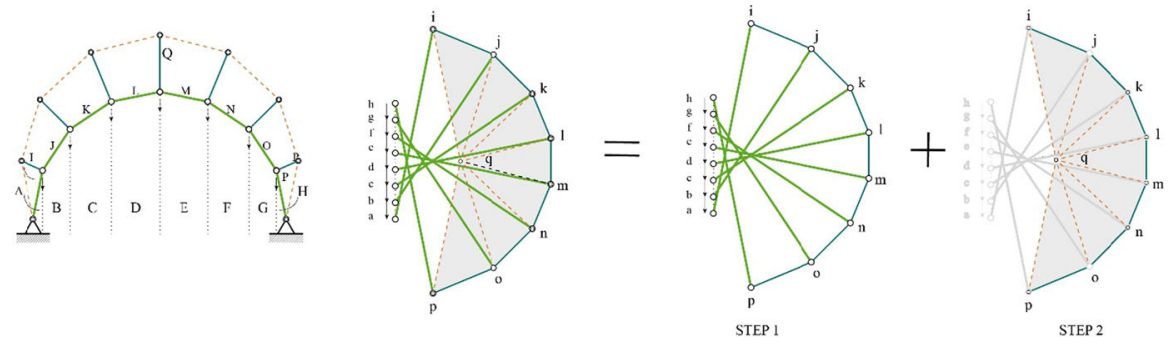

Fig. 14 Graphical construction 
- Step 2: Definition of the post-tensioning system (orange dotted line) for generating the external point loads found in Step 1.

Continuous lines represent compressive elements and forces, respectively, in form and force diagrams; while dotted lines indicate tension elements and forces, respectively, in form and force diagrams. Readers more interested in the detailed graphical construction can refer to the above mentioned references.

The graphical procedure allows the identification of an equilibrated geometry where bending moments are eliminated in each polyline vertex, and only compressive forces in the cross sections are obtained. The process starts with a given a curve and its related loads. Yet, the problem is indeterminate: an infinite number of solutions exist to make the starting geometry bending-free. This indeterminacy, which is in-depth studied in the first author's $\mathrm{PhD}$ thesis (Todisco 2016a, b), conceptually corresponds to the fact that as infinite axial-only geometries match to a single loading distribution, an infinite sets of loads correspond to a single geometry. Axial forces in the arch and the post-tensioning force applied to the tendon depend on the chosen solution: the smaller the distance between the compressive curve and the post-tensioning system, the higher the forces are in both components. In summary, given a starting geometry, and its related distribution of loads, there are infinite positions of the post-tensioning system for generating the required loads which make the starting shape a bending-free one.

\section{Implementation and Applications}

The use of graphic statics for design, as opposed to analysis, has been limited until recently, in part because a variation of the geometry or loads changes the model and the graphical construction, which must be updated, and is time-consuming to complete manually. In order to overcome this limitation, a new interactive tool for finding the layout of external post-tensioning systems has been developed. It is interactive in that a change of the geometry of the starting shape automatically results in a new post-tensioning layout in static equilibrium, which is ensured by the dual reciprocity between the force diagram and form polygon. The new tool implemented for this specific research within the Rhinoceros/Grasshopper framework (McNeel 2014a, b), is named EXOEquilibrium (it can be downloaded for free by sending an email to the first author).

Input data are represented by the geometry of the two-dimensional structure, the number of segment in which the curve should be divided (the curve is transformed in a polyline), the magnitude of permanent loads, and the direction of the struts connecting the compressive curve with the post-tensioning system. The software has a high geometrical flexibility to allow a quickly generation, exploration and evaluation of different alternatives. Figure 15 illustrates the application of the methodology to arbitrary shapes. The collection of examples, with varying degrees of curvature and both symmetrical and asymmetrical forms, demonstrates the versatility of the methodology and the implemented tool for any two-dimensional geometry. Forces in all structural members can be read in the force diagram, giving the designer the possibility to evaluate the performance of the whole system 

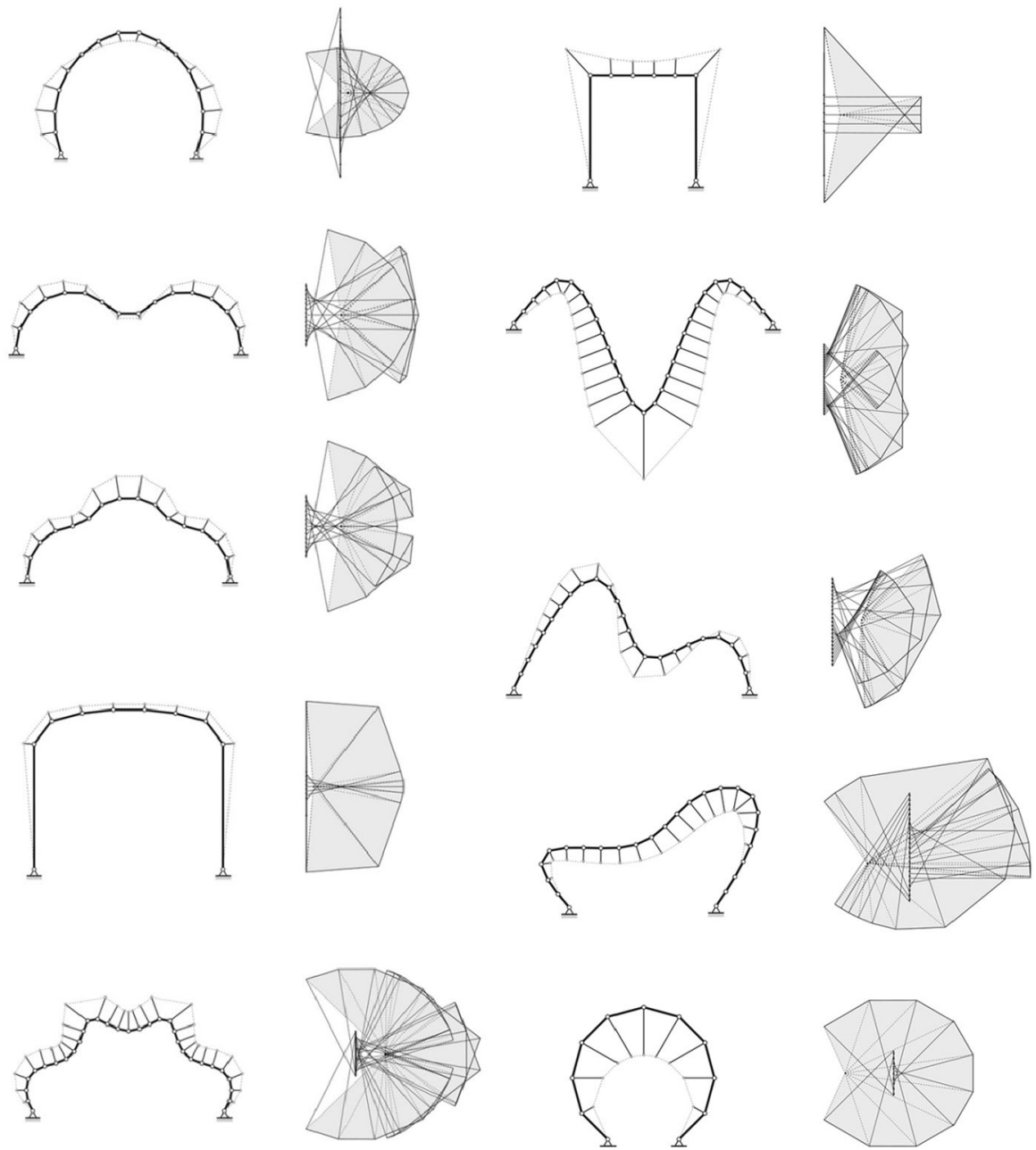

Fig. 15 Graphical construction of the external post-tensioning system applied to several geometries

consisting of the compressed geometry, the post-tensioning system, and the connecting struts.

Given a starting geometry and distribution of loads, the problem can be solved by an infinite number of equilibrated options. A specific part of the research is addressed to illustrate an original procedure that enables the optimization of this infinite domain of solutions by means of specific design criteria related to geotechnical, mechanical and aesthetic issues. These design criteria are achieved by manipulating the force diagram, instead of the form diagram, thus equilibrium is always ensured. The main conclusions are:

- The offset (i.e., maximum distance between the compressive geometry and the prestressed cable) plays a key role in optimizing the material-efficiency of the 
whole structure. Higher offset corresponds to lower material volumes, thus, more cost-effective structures.

- Specific design criteria (e.g. no horizontal thrusts, post-tensioning system always above the compression-only geometry, etc.) may require high amount of forces.

Furthermore, several applications of the graphical methodology have been developed and they are just mentioned below since their explanation would require so much space that the paper's length would be exceeded.

- The graphical procedure can be applied to a great number of problems, without limits regarding geometry, loads and support position.

- The graphical procedure can be extended to consecutive and non-planar structures.

- The graphical approach can be modified to obtain a solution where the prestress is constant in the external post-tensioning system.

\section{Experimental Testing}

Antifunicular configurations, obtained with the graphical procedure previously described, have been experimentally validated through reduced-scale models fabricated using a combination of additive manufacturing (3D printing) and lasercutting (Todisco and Mueller 2016). The physical models are composed by three elements:

- Main structure working in compression. It is made of discrete elements printed individually using a 3D printer.

- Wire. External forces are applied manually by employing a turnbuckle that provides tension to the wire.

- Connecting elements. The main structure and the wire are connected by elements made of extruded acrylic and their length is obtained from the graphical construction.

Physical experiments have been carried out with three different shapes: a basket arch, a circular arch and an asymmetrical free-form geometry. Each test was filmed using a high-speed digital video camera proving careful observation of the collapse mechanism and slow-motion videos useful for didactic purposes.

Figure 16, on the top, shows the graphical construction that allows to find the layout of the external prestressed wire and the lengths of connecting elements. Figure 16, on the bottom, illustrates photos taken during the collapse mechanism of the models after cutting the wire. Physical models show that once the posttensioning force is applied, the non-funicular shapes, made of discrete elements, are stable (i.e. the thrust line is contained in the masonry thickness). This can be considered as a first validation of the approach. Next, once the wire is cut, external forces are removed, there is no way to achieve equilibrium and the structures inevitably collapse. Experimental testing shows that non-funicular structures can be in equilibrium only if external loads are added in a proper way: a wrong position of external forces, or their lack, inevitably causes the collapse of the structure. It is 

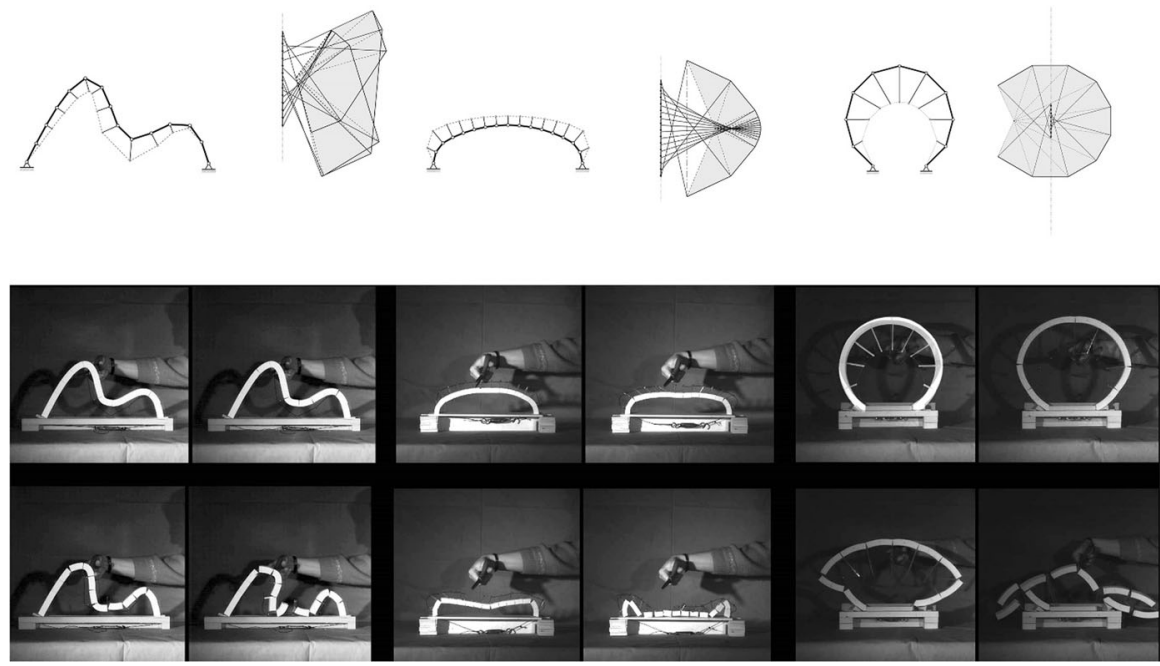

Fig. 16 Graphical constructions and collapse sequences of three reduced-scale physical models

interesting to point out that the starting position of hinges is located in zones in which the distance between thrust line (without external forces) and centroid line is maximum.

\section{Conclusions}

Modern structures rarely consider masonry as a material with a predominant loadbearing role. Its use is often related to secondary elements (e.g. cladding, pavement, handrail, etc.). In spite of that, the combination of masonry and prestress could bring this material back in vogue. This paper addresses the exploration of this combination by selecting some of the most straightforward applications of posttensioned masonry and envisages new structural typologies: specifically, posttensioned masonry arch footbridge and antifunicular structures.

The engineer is familiar with the technical aspects of prestressing, but seldom has the architectural background to exploit the structure's possibilities in layout and form. Post-tensioned masonry applied to arch and free-form structures offers new structural applications characterized by a relatively simple construction technique and relevant advantages that can move masonry to the forefront of engineering practice. The main benefits compared to traditional solutions are:

- Slenderness, achieved by minimizing the bending moments in the structure;

- Durability offered by the masonry to weather conditions and reducing maintenance costs, contributing to construction sustainability;

- Material-efficiency, achieved by increasing the efficacy of prestress with little to no loss of prestress force due to friction; 
Post-tensioning offers new potential for the revival of masonry as a structural material and this paper encourages designers to foster the use of traditional materials in innovative directions.

\section{References}

Allen, E. and W. Zalewski. 2009. Form and Forces Designing Efficient, Expressive Structures. New York: John Wiley \& Sons.

Brown, A. 2001. The engineer's contribution to contemporary architecture: Peter Rice. London: Thomas Telford Publishing

Campa, M. 2009. EE Viollet-le-Duc: Innovation and tradition in architecture. Language of form and structure in the conception of polyhedral vaults. In: Proceedings of the third international congress on construction history, ed. K.E. Kurrer, L. Werner, W. Volker, 1-8. Berlin: neunplus1

Colas, A., Garnier, D. and JC. Morel. 2013. Yield design modelling of dry joint retaining structures. Construction and Building Materials 41: 912-917

Colella, M. 2017. Structures, Algorithms and Stone/Timber Prototypes. Nexus Network Journal 19(1): 209-215

Cremona, L. 1872. Le figure reciproche nella statica grafica. Milano: Tipografia di G. Bernardoni.

Culmann, K. 1864. Die graphische Statik. Zürich: Verlag von Meyer and Zeller.

Dernie, D. 2003. New stone architecture. London: Laurence King.

Dickson, M.G.T. and G.R. Werran. 1999. The Post-Tensioned, Prestressed Ketton Stone Perimeter Frame of The Queen's Building, Emmanuel College, Cambridge. The Structural Engineer 77 (20): 19-29

Fallacara, Giuseppe and Mauriziom Barberio. 2017. Parametric morphogenesis, robotic fabrication \& construction of novel stereotomic hypar morphologies: Hypar Gate, Hypar Wall and Hypar Vault. In: Handbook of Research on Form and Morphogenesis in Modern Architectural Contexts, ed. D’Uva Domenico, 329-353. Hershey: IGI Global. https://www.igi-global.com/chapter/parametricmorphogenesis-robotic-fabrication-and-construction-of-novel-stereotomic-hypar-morphologies/ 198095. Accessed 2 October 2017.

Fallacara, G., Brocato, M. and L. Tamborero. 2010. E. E. Viollet-le-Duc et les ossatures constructives mixtes: spéculations morphologiques et constructives sur le thème de l'arc armé, IIe colloque international de Pierrefonds. http://www.atelierfallacara.it/_download/Articoli/47.pdf. (accessed 1 Nov 2017).

Fivet, C. and D. Zastavni. 2012. Robert Maillart's key methods from the Salginatobel Bridge design process (1928). Journal of the International Association for Shell and Spatial Structures 53(171): 39-47.

Fivet, C. and D. Zastavni. 2015. A fully geometric approach for interactive constraint-based structural equilibrium design. Computer-Aided Design 61(0), 42-57.

Heyman, J. 1966. The stone skeleton. International Journal of Solids and Structures 2(2): 249-279.

Kawaguchi, Mamoru. 2002. On how concrete spatial structures can be beautiful. In: Proceedings of the 1st fib Congress, ed. International Federation for Structural Concrete, 1-12. Osaka: Prefectural Government

Lancaster, L. C. 2005. Concrete Vaulted Construction in Imperial Rome. New York: Cambridge University Press.

Lenczner, E. 1994. The Design of the Stone Facade to the Pavilion of the Future, Expo'92, Seville. The Structural Engineer 72(11): 171-177.

Leonhardt, F. 1964. Prestressed concrete; design and construction. Berlin: W. Ernst.

Lin, T.-Y. 1963. Design of prestressed concrete structures. New York: Wiley.

Malomo, Daniele. and Valerio Varano. 2015. Lithic Hypar: New Frontiers in Structural Stone's Research. In Proceedings of the COMSOL Conference 2015. Grenoble: COMSOL Conference.

Martinez, J. L. 2003. Determinación teórica y experimental de diagramas de interacción de esfuerzos en estructuras de fábrica y aplicación al análisis de construcciones históricas. Ph.D. Thesis, Universidad Politécnica de Madrid.

McNeel, R. 2014a. Grasshopper generative modeling for Rhino. Computer software.

McNeel, R. 2014b. Rhinoceros NURBS modeling for Windows. Computer software. 
Misiunaite, I. 2013. Structural Behaviour and Stability of Steel Beam-Column Elements in Under-Deck Cable-Stayed Bridge. Ph.D. Thesis, VGTU leidykla Technika.

Pirard, A. 1967. La Statique graphique: statique graphique, science introductive à l'art de construire. Liège: Vaillant-Carmanne.

Potenza, D. 2005. La pietra armata: concezione e costruzione della chiesa di padre Pio, progettata da Renzo Piano. Foggia: Grenzi.

Ramos-Casquero, A. 2016. Caracterización estructural de los rellenos situados en el trasdós de bóvedas de edificios históricos. Ph.D. Thesis, Universidad Politécnica de Madrid.

Romo, Jose. 2017. Los puentes de piedra: visiones desde la Ingeniería y las Ciencias Sociales. In: Los puentes de piedra (o ladrillo) antaño y hogaño, eds. Javier León and José Maria Goicoloa, 229-241. Madrid: Fundación Juanelo Turriano.

Ruiz-Teran, A. M. and A.C. Aparicio. 2007. Two new types of bridges: under-deck cable-stayed bridges and combined cable-stayed bridges - the state of the art. Canadian Journal of Civil Engineering 34(8): 1003-1015.

Sanmartín, A. 1998. Una prospectiva de las tecnologías de las estructuras espaciales. Los puentes. Informes de La Construcción 50(455): 53-63.

Stocks, E. 2017. Estudio tipológico de bóvedas pretensadas de fábrica. Master thesis, Universidad Politécnica de Madrid.

Strasky, J. 2003. The power of prestressing. Structural Concrete 4(1): 25-43.

Strasky, J. 2005. Stress ribbon and cable-supported pedestrian bridges. London: Thomas Telford.

Todisco, L. 2016. Funicularity and Equilibrium for High-Performance Conceptual Design. Ph.D. Thesis, Universidad Politécnica de Madrid

Todisco, L., Corres, H. and C. Mueller. 2016. Funicularity through External Posttensioning: Design Philosophy and Computational Tool. Journal of Structural Engineering 142(2): 1-9.

Todisco, L. and H. Corres. 2017. New opportunities for the conceptual design of material-efficient antifunicular structures. Hormigón Y Acero. https://doi.org/10.1016/j.hya.2017.04.010

Todisco, L., Fivet, C., Corres, H. and C. Mueller 2015. Design and exploration of externally posttensioned structures using graphic statics. Journal of the International Association for Shell and Spatial Structures 56(4): 249-258.

Todisco, L. and C. Mueller 2016. Externally post-tensioned structures: Validation through physical models. In: Proceedings of the 3rd International Conference on Structures and Architecture, ed. Paulo Cruz, 1144-1151. Guimarães: ICSA.

Van Mele, T., Lachauer, L., Rippmann, M. and P. Block. 2012. Geometry-based understanding of structures. Journal of the International Association for Shell and Spatial Structures 53(174): 285-295.

Varignon, P. 1725. Nouvelle mécanique ou statique 1. Paris: Jombert.

Viollet-le-Duc, E. 1863-1872. Entretiens sur l'architecture. Paris: Q. Morel et cie

Wolfe, W. S. 1921. Graphical analysis; a text book on graphic statics. New York: McGraw-Hill book Co.

Leonardo Todisco is a structural engineer at FHECOR Consulting Engineers and he holds a Venia Docendi professorship at the Technical University of Madrid, Spain. He earned a Ph.D and a M.Eng. in Structural Engineering from the Technical University of Madrid and a M.Sc. and a B.Sc. in Civil Engineering from the Technical University of Bari, Italy. His research interests include shear strength of RC members, masonry structures and conceptual design of structures. He was awarded the 13th IASS Hangai Prize and the UPM PhD Excellence Award. Leonardo is co-founder of Apuliabase, a start-up working on the conservation, analysis and restoration of the Architectural Heritage.

Elizabeth Stocks is a civil and structural engineer currently working in the Madrid office of Ove Arup and Partners. She graduated with an MSc and BSc in Civil Engineering from the Technical University of Madrid as well as taking part in an exchange program in University of California, Berkeley. During her academic career, she worked on the conceptual design of a footbridge in Madrid Rio. She is currently working on projects related to seismic assessment by making use of pushover analysis in masonry structures. 
Javier León is a civil engineer since 1981 and got his $\mathrm{PhD}$ in 1987, both at the Civil Engineering School of Madrid. He is professor of Structural Concrete since 1989. Since 1999, he is also been responsible of Analysis of historical masonry structures. In 2015 he started teaching Maintenance Engineering in the field of existing structures. He was also General Secretary of the Spanish Structural Concrete Association between 1990 and 1999. His areas of activity are related to existing structures of any typology, age or material.

Hugo Corres graduated as a Civil Engineer in 1977, and obtained his PhD in 1981, both from the Technical University of Madrid. He is also a Doctor Honoris Causa from the Technical University of Bratislava. Hugo is a Full Professor of Structural Concrete and Conceptual Design at the School of Civil Engineering at the Technical University of Madrid, since 1993. He is fib President, and a former President of ACHE, Spanish Structural Concrete Scientific Association. He founded FHECOR Consulting Engineers, and has designed several concrete and steel bridges and a large number of major buildings. 